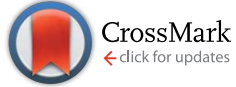

Cite this: Soft Matter, 2014, 10, 7797

\title{
Surface micro/nanotopography, wetting properties and the potential for biomimetic icephobicity of skunk cabbage Symplocarpus foetidus
}

\begin{abstract}
Rahul Ramachandran and Michael Nosonovsky*
Lotus (Nelumbo nucifera) is known for its two remarkable properties: superhydrophobicity and thermogenesis; however, the relationship between these two properties remains obscure. Most botanists agree that thermogenesis helps to attract pollinators, while non-wetting helps to catch pollinators and prevents contamination. Here we investigate the surface micro- and nanotopography and wetting properties of eastern skunk cabbage (Symplocarpus foetidus), another thermogenic plant, which is known for its ability to melt snow. The skunk cabbage leaves are hydrophobic but not superhydrophobic, and they have high contact angle hysteresis (similar to the rose petal effect). We develop a heat transfer model to relate icephobicity with heat transfer and discuss the biomimetic potential that both thermogenic and superhydrophobic plants may have for icephobicity in soft materials.
\end{abstract}

Received 7th June 2014

Accepted 28th July 2014

DOI: $10.1039 / \mathrm{c} 4 \mathrm{sm} 01230 \mathrm{e}$

www.rsc.org/softmatter

hysteresis being wetting characteristics during normal and

\section{Introduction}

Superhydrophobicity, also known as the lotus effect, has become an object of intensive studies in the past decade leading to a number of important findings and technology advances in producing self-cleaning, water-repellent, omniphobic, antifouling, and icephobic surfaces. ${ }^{1-14}$ The lotus (Nelumbo nucifera) leaf with its hierarchical structure of papillae covered with rough wax served as an initial source of inspiration for the artificial superhydrophobic surfaces. A superhydrophobic surface typically has an apparent water contact angle (CA) greater than $150^{\circ}$ and small CA hysteresis, i.e., the difference between the advancing and receding CAs. The topography of a surface affects its wetting state. ${ }^{15,16}$

The studies of hydrophilic and hydrophobic plants also revealed another interesting phenomenon, which was called the rose petal effect. The rose petal has a high CA, often in the superhydrophobic region and, at the same time, strong adhesion with water and, therefore, large CA hysteresis. The observation caused a discussion of the very concept of hydrophobicity and how it is possible for a surface to be "superhydrophobic" (meaning the strong repellence of water) simultaneously with having strong adhesion to water. ${ }^{8,9}$ An alternative term suggested for the rose petal effect in the literature is the "parahydrophobic state". ${ }^{17}$ Among the proposed answers was that water-to-solid adhesion is not characterized by a single number, such as the apparent CA. Instead, the normal and shear loading can be considered separately, presumably, with the CA and CA

College of Engineering \& Applied Science, University of Wisconsin-Milwaukee, Milwaukee, WI 53211, USA. E-mail: nosonovs@uwm.edu; Fax: +1-414-229-6958; Tel: $+1-414-229-2816$ shear loadings. Shear and normal loads can be applied and measured independently using the centrifugal adhesion balance. ${ }^{14}$ Furthermore, the very concept of static CA is not well defined since the CA may depend on how the water droplet was created and does not necessarily converge with time to a single value. ${ }^{18}$ It has also been shown recently that surfaces can exhibit a high contact angle coupled with either low or high adhesion by virtue of surface topography alone. ${ }^{19}$

Icephobicity, or the ability to repel ice, constitutes another class of property related to superhydrophobicity. The exact definition of icephobicity remains the subject of debate, as well as its relationship with superhydrophobicity. ${ }^{20-26}$ However, given that ice will form on any surface, the parameter of practical importance is the work of adhesion between the substrate and ice. ${ }^{26}$

Besides superhydrophobicity, another property which is unusual in lotus is thermogenesis. Thermogenic plants, including the lotus, can raise their temperature above that of surrounding air, sometimes exceeding the latter by $20{ }^{\circ} \mathrm{C}$. The role of thermogenesis in plants is still debated by botanists; however, the most popular hypothesis is that heat helps to spread chemicals that attract pollinators to the plant. ${ }^{27,28}$ Heat is generated in mitochondria of the plant cells. Besides lotus, only a few plants have thermogenic properties including some tropical plants, such as the voodoo lily (Amorphophalus), and some plants common in the northern climate including the eastern skunk cabbage (Symplocarpus foetidus, also referred to in the literature as eastern North American skunk cabbage) and several related plants from the Araceae (arum) family. The skunk cabbage is known for its ability to emerge from under snow. 
Apparently, there is no direct correlation between superhydrophobicity and thermogenesis, since besides lotus there are no examples of plants which possess both properties. However, since these both properties may involve certain common features, such as the ability to repel ice, the issue requires further investigation. In this paper we study leaves of a thermogenic plant, S. foetidus, and develop a model that can explain the link between superhydrophobicity, thermogenesis and icephobicity.

\section{S. Foetidus and icephobicity}

Eastern skunk cabbage ( $S$. foetidus) is a member of the Araceae family and is of particular interest due to its peculiar thermogenic and thermoregulatory properties. The plant is native to North American wetlands. It blooms in late winter or early spring, when there is still a snow cover on the ground. The ability of the plant to survive and melt through thick snow under below-freezing ambient conditions is of interest to us.

The parts of the skunk cabbage shoot are the green leaves (Fig. 1a) and the purple modified leaves called spathes (Fig. 1b) which enclose the flowering part of the plant called spadix. It is the spadix which emits the foul smelling odor that gives the plant its name. Spadix also plays an important role in thermogenesis. The plant is able to maintain an average spadix temperature of $15{ }^{\circ} \mathrm{C}$ when the ambient temperature is -15 ${ }^{\circ} \mathrm{C} .{ }^{29}$ Transpiration plays an important part in regulating the plant temperature. In hot tropical climate, thermogenic plants like lotus maintain their temperature below that of surroundings by evaporating water. Similarly, plants reduce the water loss by evaporation to maintain temperatures above that of surroundings. In plants, the water loss to the atmosphere and gaseous exchange occur through openings on the leaf surface called stomata. Usually leaves of terrestrial plants have stomata on their lower (abaxial) surface. Aquatic plants like lotus have

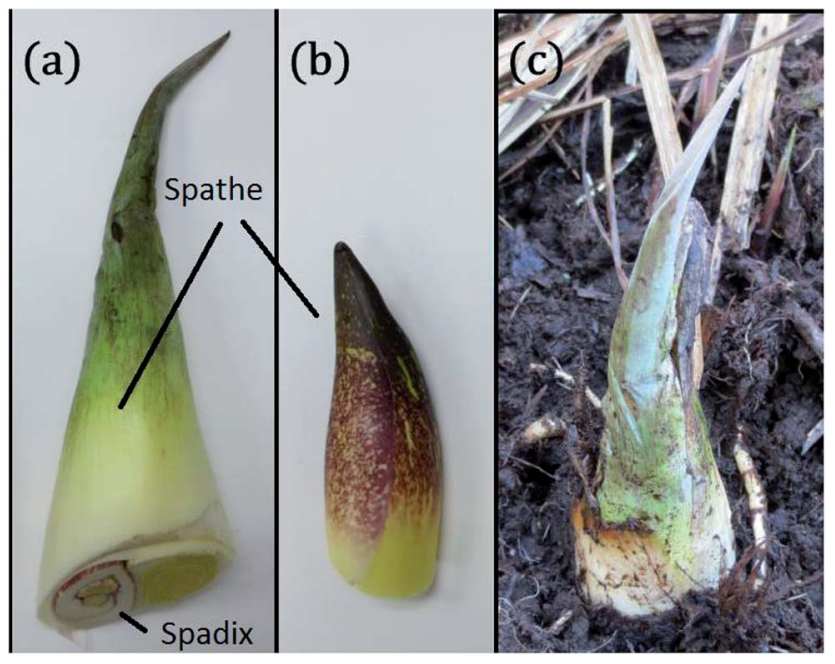

Fig. 1 (a) The leaf of skunk cabbage enclosing spathe and spadix, and (b) the spathe. (c) Skunk cabbage as observed in its natural environment in the wet land (Schlitz Audubon Nature Center, Milwaukee, WI) in the month of November. stomata on their upper (adaxial) surface. Many plant leaves are usually covered by a thin wax coating called the cuticle whose one of many functions is to prevent an excessive water loss. The cuticle is sometimes further covered with epicuticular wax crystals of different geometries like platelets, tubules, rodlets etc. $^{30}$ The size and geometry of these wax crystals are some of the decisive factors in the wetting state of the leaf, e.g. lotus leaf.

The thermogenesis of skunk cabbage is well documented in the literature. ${ }^{29,31,32}$ There have been studies on the heat generation at the spadix. But according to the authors' knowledge, there has been no study on regulation of heat loss through the leaves or spathes and on the plant's icephobic properties. Here we study the surface morphology of the leaves and spathes of skunk cabbage and how it may help in regulating the heat loss.

\subsection{Does it fit the definition of icephobicity?}

Prior to discussing the icephobic properties of skunk cabbage we should revisit the definition of icephobicity, since the term is often used by different authors with somewhat different meanings. The words "icephobic" and "icephobicity" have been used in the literature for some time, and the first documented use goes back to the late 1940s: "urgently needed are coatings of one kind or another that prevent or lessen adhesion of ice to various kinds of surfaces. An engineer in the Navy Department's Bureau of Ships coined a word to succinctly describe such coatings: "icephobic." Need for such materials is not confined to military ships, guns and planes: in war or peace ice is a problem on railroad switch frogs, electrical conductor rails or trolley wires, signal mechanisms, refrigerator freezing units, valves and other equipment exposed to wintry weather, and-of course-commercial aircrafts and marine vessels.". ${ }^{33}$

The term "icephobic" is analogous to hydrophobicity and other "-phobicities" which are common in physical chemistry (oleophobicity, lipophobicity, omniphobicity, amphiphobicity, etc.). A discussion of possible thermodynamic definition of icephobicity is found in.ref. 34. The extensive controversy among scholars on whether icephobicity is related to superhydrophobicity came to a conclusion that there is no direct correlation. $^{21,24,35}$

There are multiple approaches to characterize icephobic surfaces. One approach uses the critical shear (or normal) stress between ice and the surface. Surfaces with shear strength between $150 \mathrm{kPa}$ and $500 \mathrm{kPa}$ (ref. 26 and 36) and even as low as $15.6 \mathrm{kPa}$ (ref. 37) are called icephobic. Another uses delay in ice nucleation and freezing. A third approach defines icephobic surfaces by their ability to repel small incoming droplets at freezing temperatures. ${ }^{38,39}$

The above three approaches correspond to three different, although related, properties of anti-icing surfaces, which prevent freezing of condensing water, prevent freezing of incoming water, and have weak adhesion with any ice formed. Mechanical properties of ice and the substrate are also of great importance since removal of ice occurs by fracture, either in the mode I (normal) or mode II (shear) cracking, so that crack concentrators are major contributors to the reduced strength. 
This makes the composite (solid-air-water or Cassie-Baxter) interface beneficial for icephobicity. ${ }^{24}$

There is a certain parallelism between the definition of icephobicity and superhydrophobicity. The latter is defined by the high water contact angle (CA) $>150^{\circ}$ and by low CA hysteresis, although very high CA can co-exist with high CA hysteresis (the rose petal effect $^{18}$ ). Low CA hysteresis corresponds to shear mode of loading at the solid-water interface while a high CA corresponds to the normal loading. The ability to bounce-off incoming droplets constitutes the third aspect of superhydrophobicity. ${ }^{40}$

The ability of the skunk cabbage to repel ice formation is likely to be related to the elevated temperature of the leaves rather than to the surface structure, however, the surface microstructure should be investigated.

\section{Experimental}

A sample of the plant was collected in early November from a wet land in Milwaukee. The plant had none of its large leaves left at this time of the year. All that remained above ground was the spadix enclosed in a spathe and fresh unsprouted leaves, prepared to weather the long and frigid winter (Fig. 1c). Water contact angles (WCA) on the spathe and leaf surfaces of a freshly cut plant (within three hours after cutting) were measured using a goniometer (Ramé-Hart). The microstructures of the leaf and spathe surfaces were studied using scanning electron microscopy (SEM).

\subsection{SEM sample preparation}

Three different sets of samples of leaves and spathes were prepared. Biological specimens, such as cells and tissues or tissue components, must first be fixed to preserve their native structure. Chemical fixation typically uses formalin or glutaraldehyde of varying percent concentrations in a buffer of a specific $\mathrm{pH}$. The first set (S1) was air dried in a desiccator for over two days at room temperature. ${ }^{41}$ The second set (S2) was prepared by chemical fixation in the liquid phase. A $10 \mathrm{ml}$ aqueous solution of $2.5 \%$ glutaraldehyde, $0.1 \mathrm{M}$ HEPES buffer (pH 7.2) and $0.02 \%$ triton $\mathrm{X}-100$ was prepared and the samples were left overnight in the solution. The samples were then washed thrice with distilled water and then left overnight in an $8 \mathrm{ml}$ aqueous solution of $1 \%$ osmium tetroxide. The samples were then dehydrated in a series of steps using anhydrous ethanol in $20 \%, 40 \%, 60 \%, 80 \%$ and $100 \%$ (thrice) solutions. This was followed by critical point drying (Blazers CPD 020) to remove ethanol from the samples.

Since triton X-100 removes all the epicuticular wax, a third set (S3) of samples were prepared using vapor phase fixation ${ }^{42}$ to maintain the structure of the cells, while retaining the waxes on the surface. Samples were first exposed to vapor of $2 \%$ glutaraldehyde and then $2 \%$ osmium tetroxide both at room temperature.

All three sample sets were fixed on aluminum stubs using double sided tape. Then they were sputter coated in an Emitech K575X sputter coater with an Irridium target. The thickness of coating varied based on the fixation procedure $-\mathrm{S} 1$ required 4 $\mathrm{nm}$ while $\mathrm{S} 2$ required $5 \mathrm{~nm}$ and $\mathrm{S} 3$ required $8 \mathrm{~nm}$. Colloidal carbon paint was applied along the edges of the samples on stubs to further reduce charging. The paint was applied using a fine brush under an optical microscope to ensure that leaf surfaces remained intact. The samples were observed in a Hitachi S-4800 FE-SEM.

\section{Results}

The surfaces of both the leaf and spathe were seen to be hydrophobic (Fig. 2(a and b)). The leaf surface showed an average WCA of $92^{\circ}$ and the spathe surface showed an average WCA of $97^{\circ}$. The surfaces also showed extremely high adhesion, with the water droplet not rolling off the vertical surface (Fig. 2(c)). The advancing and receding CAs on the leaf surface was $110^{\circ}$ and $83^{\circ}$, respectively, with a CA hysteresis of $27^{\circ}$. This is similar to the rose-petal effect where the droplet is usually thought to be in the Cassie-Baxter impregnating wetting state. On the other hand, Marmur showed that the contact area of a drop with the solid in the Wenzel state can be higher by orders of magnitude compared with the Cassie-Baxter state, for the same contact angle. ${ }^{43}$ It is therefore possible that a high contact angle and an "adhesive" drop indicate the Wenzel "parahydrophobic" state. ${ }^{17}$

It was seen that the vapor phase fixation procedure (sample set S3) yielded the best scanning electron micrograph results while preserving the structure of the epicuticular wax crystals. The sample sets $\mathrm{S} 1$ and $\mathrm{S} 2$ did not preserve the wax crystals. But S2 provided insight into the underlying microstructure. The scanning electron micrographs of the adaxial and abaxial surfaces of both the leaf and the spathe are shown in Fig. 3. The abaxial surface of the leaf showed pillars $(\sim 10 \mu \mathrm{m}$ diameter $)$ coated with wax rodlets (Fig. 3(e-g)). The adaxial surface of the leaf displayed a different surface texture with lack of pillar like structures and visibly far less density of wax rodlets (Fig. 3(a and b)). The adaxial and abaxial surfaces of the spathe also showed an absence of pillar like structures and dense wax rodlets (Fig. 3(c and d)). Interestingly, the adaxial surface of the leaf and the adaxial and abaxial surfaces of the spathe carried stomata, with the spathe showing a denser distribution of stomata. But the stomata on the abaxial surface of the leaf lay beneath the dense canopy of wax rodlets.

Skunk cabbage is known to survive the sub-zero temperatures of winter and bloom in late winter or early spring. The

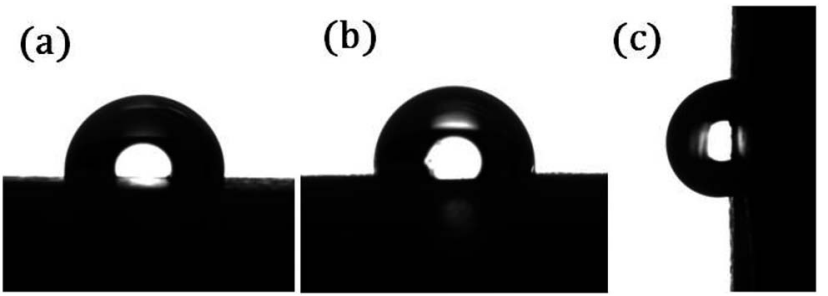

Fig. 2 Water droplets on (a) leaf (b) spathe (c) an adherent water droplet on the vertical surface of the leaf. 

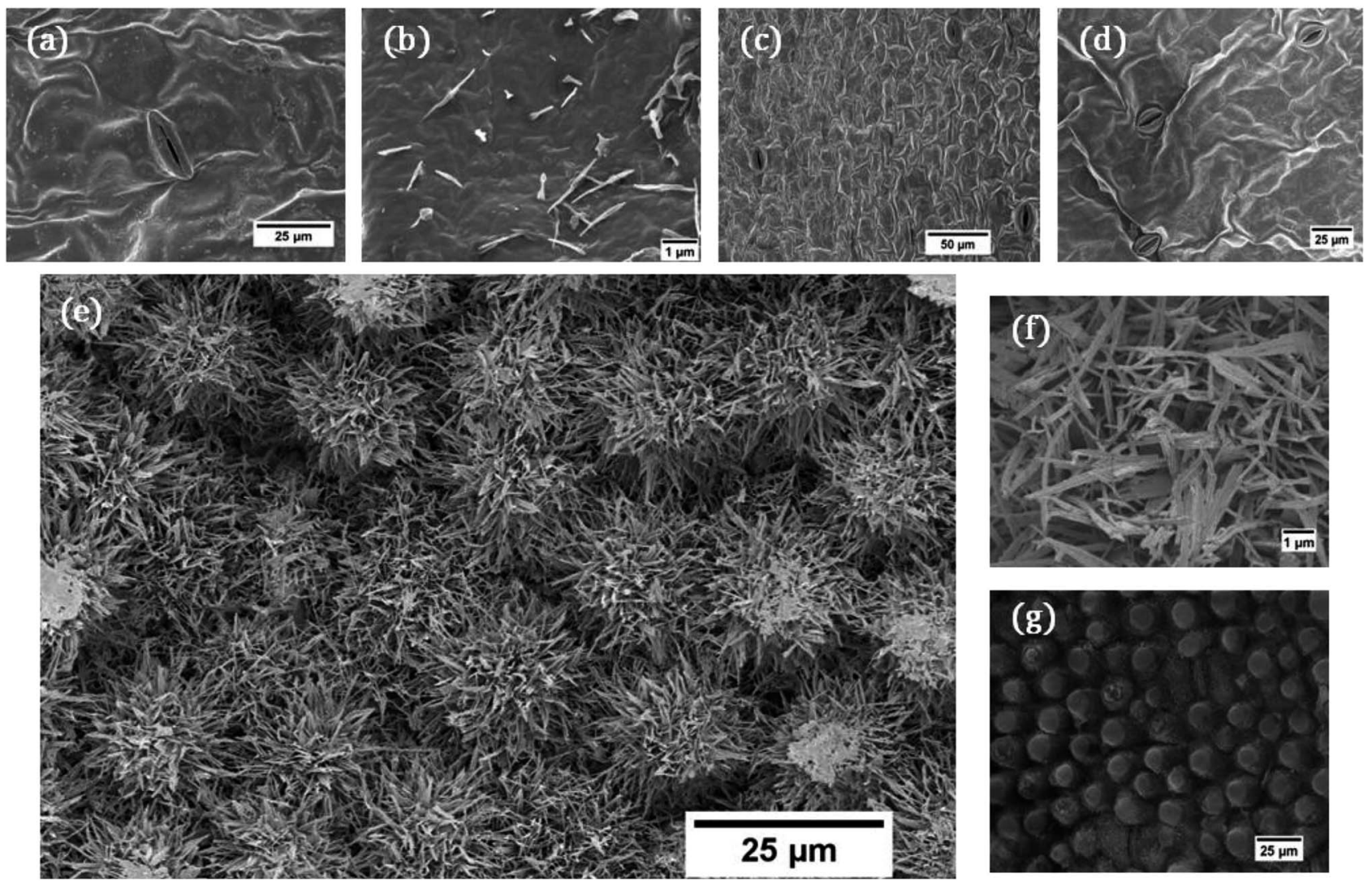

Fig. 3 Scanning electron micrographs of skunk cabbage leaf and spathe surfaces. (a) Vapor phase fixed adaxial leaf surface, (b) scarcely distributed wax rodlets on the adaxial leaf surface, (c) adaxial surface of vapor phase fixed spathe showing stomata (d) abaxial surface of vapor phase fixed spathe showing stomata, (e) vapor phase fixed abaxial leaf surface showing pillars covered with wax rodlets, (f) the wax rodlets, and (g) liquid phase fixed abaxial surface of the leaf showing the pillars tops void of wax rodlets.

abaxial surface of the leaf is all that covers the spathe and spadix of the plant during extremely cold winters. Therefore, from the stand point of conserving heat, it seems logical to have fewer numbers of stomata on the surface exposed to the outside weather. Stomata directly connect the interstitial spaces below the epidermis to the environment for transpiration. Reduced transpiration means minimal heat loss to the surroundings.

The abaxial surface showed hierarchical roughness with high adhesion. ${ }^{44}$ This may be similar to the high contact angle coupled with high hysteresis seen in leaves of plants like garlic and scallion of genus Allium. Such leaves have a rough surface covered with epicuticular wax which results in a high contact angle. But they also have strong smelling diallyl disulphide, a hydrophobic defect which causes contact line pinning, and thus high contact angle hysteresis. ${ }^{45}$ Skunk cabbage is known to have dimethyl disulphide which is known to volatilize and cause the peculiar smell associated with the plant. ${ }^{46}$ The dimethyl disulphide might be acting as hydrophobic defects on the skunk cabbage leaf resulting in high adhesion coupled with hydrophobicity.

In addition, a freezing test was performed. A small piece $(2 \times$ $2 \mathrm{~cm}$ ) of skunk cabbage leaf was cut and a water droplet was placed on it. After that, the leaf was placed in the freezer of a kitchen refrigerator (temperature $-5{ }^{\circ} \mathrm{C}$ ). Several hours later, after the water droplet froze, the leaf was removed.
The ice droplet was stuck to the leaf surface demonstrating relatively strong adhesion and thus no icephobic property of the cut leaf was found.

\section{Discussion}

The above results show that the leaf has complex micro- and nanotopography which affects its wetting properties. The leaf is hydrophobic, however, no superhydrophobic properties were found. A cut leaf demonstrates strong adhesion to ice. This implies that the living leaf repels ice/snow due to its thermogenic properties. Below we suggest a simple model which relates the heat flow to the surface structure and wetting properties.

Consider a leaf surface at temperature $T_{1}$, initially covered with a layer of ice at temperature $T_{2}$ and thickness ' $a$ '. It is assumed that the leaf surface maintains a steady temperature and the heat loss to the surrounding air is neglected. The leaf surface is rough and forms a solid-liquid-vapor composite interface as shown in Fig. 4(a). When $T_{1}>T_{2}$, heat flows from the plant surface to ice and it melts to form water. At any time $t$, let the water-ice interface be located at a distance ' $x$ ' from the plant surface. The heat flow from the leaf to ice can be written as. 


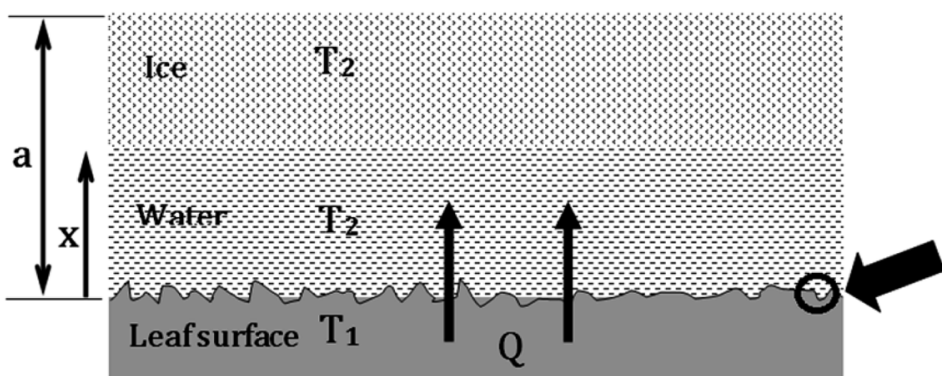

(a)

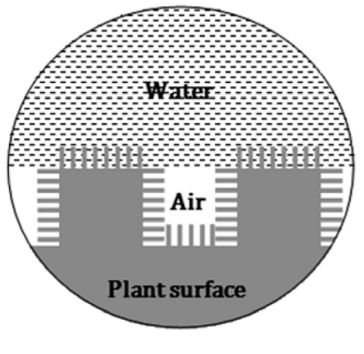

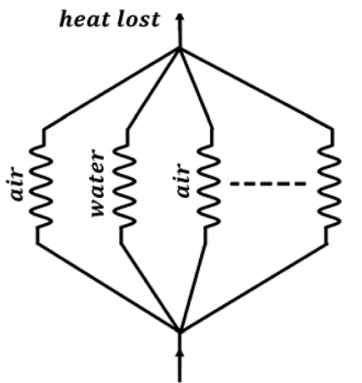

(b)

Fig. 4 (a) Heat transfer at the composite interface on the leaf surface resulting in melting of ice and an advancing water-ice interface (b) equivalent electrical circuit showing thermal resistances at the composite interface.

$$
Q=L A \frac{\mathrm{d} x}{\mathrm{~d} t}
$$

where $L$ is the latent heat of fusion of ice, $A$ is the projected area of the leaf surface and $\frac{\mathrm{d} x}{\mathrm{~d} t}$ is the velocity at which the water-ice interface advances. In order to reach the water-ice interface, this heat has to flow through the water, as well as the leaf-water interface. Therefore

$$
\begin{gathered}
Q=h_{\mathrm{W}} A\left(T_{\mathrm{i}}-T_{2}\right) \text { and } \\
Q=\frac{T_{1}-T_{\mathrm{i}}}{R_{\mathrm{th}}}
\end{gathered}
$$

where $T_{\mathrm{i}}$ is the leaf-water interface temperature, $h_{\mathrm{W}}$ is the heat transfer coefficient of water and $R_{\mathrm{th}}$ is the thermal resistance of the composite interface. From eqn (2) and (3),

$$
Q=\frac{T_{1}-T_{2}}{\frac{1}{h_{\mathrm{W}}}+R_{\mathrm{th}}}
$$

The thermal resistance of the composite interface can be represented as electrical resistors connected in parallel as shown in Fig. 4(b). If $f_{\mathrm{WA}}$ is the fractional flat area of the waterair interface,

$$
1 / R_{\mathrm{th}}=h_{\mathrm{A}} A f_{\mathrm{WA}}+h_{\mathrm{W}} A\left(1-f_{\mathrm{WA}}\right)
$$

Combining eqn (1), (4) and (5) we get,

$$
\left(\frac{1}{h_{\mathrm{W}}}+\frac{1}{h_{\mathrm{A}} f_{\mathrm{WA}}+h_{\mathrm{W}}\left(1-f_{\mathrm{WA}}\right)}\right) \mathrm{d} x=\left(T_{1}-T_{2}\right) \mathrm{d} t
$$

$$
\begin{aligned}
& \text { Integrating } \\
& \frac{L}{\left(T_{1}-T_{2}\right)}\left(\frac{1}{h_{\mathrm{W}}}+\frac{1}{h_{\mathrm{A}} f_{\mathrm{WA}}+h_{\mathrm{W}}\left(1-f_{\mathrm{WA}}\right)}\right) \int_{0}^{a} \mathrm{~d} x=\int_{0}^{t} \mathrm{~d} t \text {, we get }
\end{aligned}
$$
the time required to melt an ice layer of thickness ' $a$ ',

$$
t=\frac{L a}{\left(T_{1}-T_{2}\right)}\left(\frac{1}{h_{\mathrm{W}}}+\frac{1}{h_{\mathrm{A}} f_{\mathrm{WA}}+h_{\mathrm{W}} r_{\mathrm{f}}\left(1-f_{\mathrm{WA}}\right)}\right)
$$

If the water-air interface has a roughness factor $r_{\mathrm{f}}$, then

$$
t=\frac{L \mathrm{a}}{\left(T_{1}-T_{2}\right)}\left(\frac{1}{h_{\mathrm{W}}}+\frac{1}{h_{\mathrm{A}} f_{\mathrm{WA}}+h_{\mathrm{W}} r_{\mathrm{f}}\left(1-f_{\mathrm{WA}}\right)}\right)
$$

The plots in Fig. 5 are obtained using nominal values of $h_{\mathrm{A}}=$ $10 \mathrm{~W} \mathrm{~m}^{-2} \mathrm{~K}^{-1}, h_{\mathrm{w}}=20 \mathrm{~W} \mathrm{~m}^{-2} \mathrm{~K}^{-1}, L=334 \mathrm{~kJ} \mathrm{~kg}^{-1}, T_{1}=15^{\circ} \mathrm{C}$ and $T_{2}=0{ }^{\circ} \mathrm{C}$. As the wetted area of the leaf surface decreases, the longer it takes for the heat transfer to occur (Fig. 5(a)). Therefore more the air pockets on the leaf surface, the longer the heat is retained. Fig. 5(b) shows that as the surface becomes rougher, the heat loss speeds up. It is also seen that roughness is a predominant factor for heat loss only when the fractional flat area of the water-air interface $\left(f_{\mathrm{WA}}\right)$ is low. As $f_{\mathrm{WA}}$ increases, the effect of $r_{\mathrm{f}}$ on the heat loss wanes.

From the above discussion, it is clear that changing the surface texture $\left(r_{\mathrm{f}}\right.$ and $\left.f_{\mathrm{WA}}\right)$ can either help to conserve heat in

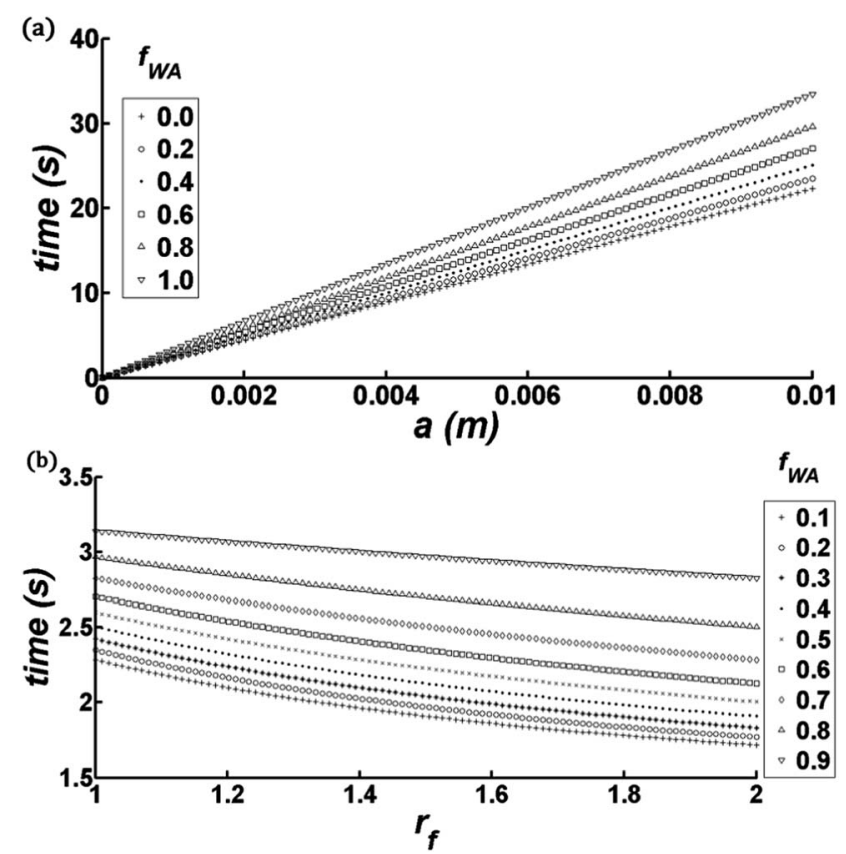

Fig. 5 (a) Time for melting of ice layers (thickness, a) at different fractional flat areas of the water-air interface and (b) time for melting an ice layer $1 \mathrm{~mm}$ thick at different fractional flat areas of the water-air interface $\left(f_{\mathrm{WA}}\right)$ and roughness factors $\left(r_{\mathrm{f}}\right)$. 


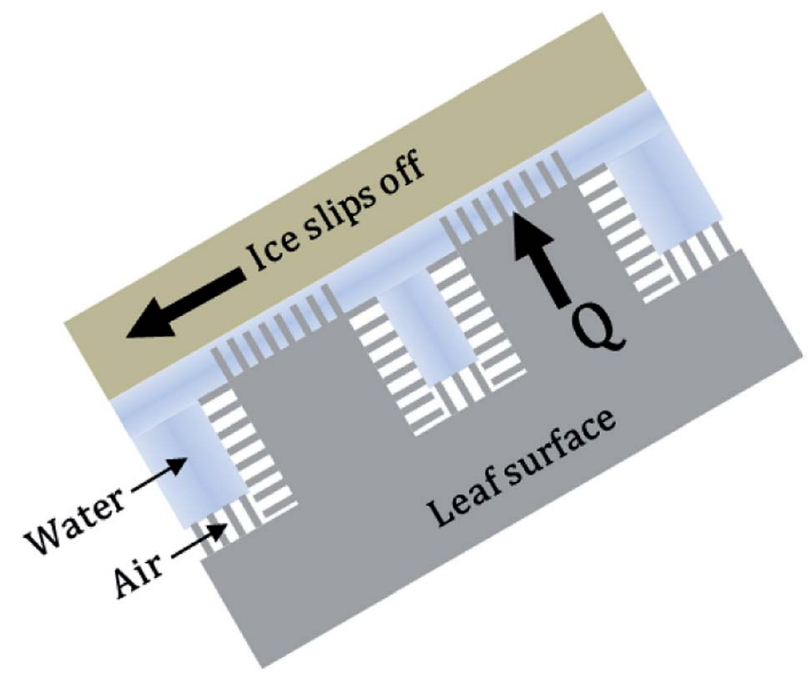

Fig. 6 The heat produced by the skunk cabbage plant in tandem with the high adhesion can maintain a slippery layer of water on the leaf surface. Thus the ice slips off the leaf surface.

extreme cold, or melt the ice cover. In the case of skunk cabbage leaf, water droplets are in a Cassie-Baxter impregnating wetting state with high adhesion possibly due to hydrophobic defects. The heat produced by the plant should be able to maintain a thin impregnated layer of liquid water and air pockets between the leaf surface and surrounding ice (Fig. 6). This ensures minimal adhesion between ice and the leaf surface, and ice readily slips off under its own weight. This process can be thought of as similar to the Nepenthes pitcher plant inspired slippery liquid-infused porous surfaces. ${ }^{\mathbf{1 3 , 4 7}}$ Also, maintaining a water-air composite interface is conducive to heat conservation because water and air have thermal conductivities of $0.56 \mathrm{~W}$ $\mathrm{mK}^{-1}$ and $0.02 \mathrm{~W} \mathrm{mK}^{-1}$ (at $275 \mathrm{~K}$, and $1 \mathrm{~atm}$ ), respectively, while ice has a thermal conductivity of $2.2 \mathrm{~W} \mathrm{mK}^{-1}$ (at $273 \mathrm{~K}$ ). Note also that the skunk cabbage plant is able to produce heat with an output up to $1 \mathrm{~W} \cdot{ }^{28}$ Given the latent heat of melting of ice to be $334 \mathrm{~J} \mathrm{~g}^{-1}$, such heat output is sufficient to melt one gram of ice in 334 seconds.

Taking inspiration from the skunk cabbage plant, surfaces with the Cassie-Baxter impregnating wetting state can be used in tandem with a heat source as functional icephobic surfaces. Such surfaces meet one of the definitions of icephobicity i.e., low adhesion between the surface and ice. The heat and the surface topography should ensure a slippery water layer on the surface. Also, the Cassie-Baxter impregnating wetting state helps to reduce heat loss compared to the Wenzel wetting state. Thus by controlling the wetting state of the surface we can control not only the contact angle and contact angle hysteresis, but also other surface properties like the local heat transfer coefficient, ice adhesion and the rate of corrosion. ${ }^{48}$

\section{Conclusions}

We studied wetting properties of the thermogenic skunk cabbage. The water contact angle was found to be $92^{\circ}$ with very high adhesion displaying the rose-petal like or "parahydrophobic" effect. The microstructure of the leaf was bumpy with hair like wax rodlets, indicating the possibility of the Cassie-Baxter impregnated wetting state with air pockets trapped between the surface and water. Experiments with ice (on a cut leaf) showed strong adhesion of ice to the surface. It is therefore likely that an elevated temperature is responsible for ice repellence in the living plant. The leaf microstructure could maintain a slippery water layer on it, reducing ice adhesion. Also, the composite interface can minimize the heat loss. As far as the biomimetic potential of the plant, we conclude that the rose-petal effect-like structure can be used to decrease the ice contact area for icephobic surfaces.

\section{Acknowledgements}

The authors would like to thank M. Smith at the Schlitz Audubon Nature Center, Milwaukee, WI for helping to collect the sample of the skunk cabbage. The authors would also like to thank H. Owen at Biological Sciences, University of Wisconsin Milwaukee (UWM) for discussions and guidance on SEM sample preparation and imaging. We also acknowledge the partial support of the UWM Research Grant Initiative grant 101X245 and National Science Foundation grant I/UCRC FRP 1331532.

\section{Notes and references}

1 C. W. Extrand, J. Colloid Interface Sci., 1998, 207, 11-19.

2 A. Marmur, Langmuir, 2003, 19, 8343-8348.

3 A. Marmur, in A Guide to the Equilibrium Contact Angles Maze, CRC Press, 2009, pp. 3-18.

4 E. Bormashenko, Y. Bormashenko, T. Stein, G. Whyman and R. Pogreb, Langmuir, 2007, 23, 4378-4382.

5 E. Bormashenko, Y. Bormashenko, G. Whyman, R. Pogreb, A. Musin, R. Jager and Z. Barkay, Langmuir, 2008, 24, 40204025.

6 E. Bormashenko, T. Stein, R. Pogreb and D. Aurbach, J. Phys. Chem. C, 2009, 113, 5568-5572.

7 E. Bormashenko, Wetting of Real Surfaces, De Gruyter, Berlin, Boston, 2013.

8 W. Li and A. Amirfazli, Adv. Mater., 2007, 19, 3421-3422.

9 S. Wang and L. Jiang, Adv. Mater., 2007, 19, 3423-3424.

10 R. Tadmor, P. Bahadur, A. Leh, H. E. N'guessan, R. Jaini and

L. Dang, Phys. Rev. Lett., 2009, 103, 266101.

11 R. Tadmor, Soft Matter, 2011, 7, 1577-1580.

12 M. Nosonovsky and B. Bhushan, Curr. Opin. Colloid Interface Sci., 2009, 14, 270-280.

13 M. Nosonovsky, Nature, 2011, 477, 412-413.

14 H. E. N'guessan, A. Leh, P. Cox, P. Bahadur, R. Tadmor, P. Patra, R. Vajtai, P. M. Ajayan and P. Wasnik, Nat. Commun., 2012, 3, 1242.

15 W. Xu, R. Leeladhar, Y. T. Kang and C. Choi, Langmuir, 2013, 29, 6032-6041.

16 J. V. I. Timonen, M. Latikka, O. Ikkala and R. H. A. Ras, Nat. Commun., 2013, 4, 2398.

17 A. Marmur, Soft Matter, 2012, 8, 6867-6870. 
18 B. Bhushan and M. Nosonovsky, Philos. Trans. R. Soc., A, 2010, 368, 4713-4728.

19 S. Peng, D. Tian, X. Miao, X. Yang and W. Deng, J. Colloid Interface Sci., 2013, 409, 18-24.

20 A. J. Meuler, G. H. McKinley and R. E. Cohen, ACS Nano, 2010, 4, 7048-7052.

21 S. A. Kulinich, S. Farhadi, K. Nose and X. W. Du, Langmuir, 2011, 27, 25-29.

22 V. Bahadur, L. Mishchenko, B. Hatton, J. A. Taylor, J. Aizenberg and T. Krupenkin, Langmuir, 2011, 27, 1414314150.

23 P. Guo, Y. Zheng, M. Wen, C. Song, Y. Lin and L. Jiang, Adv. Mater., 2012, 24, 2642-2648.

24 M. Nosonovsky and V. Hejazi, ACS Nano, 2012, 6, 8488-8491.

25 L. B. Boinovich and A. M. Emelyanenko, Mendeleev Commun., 2013, 23, 3-10.

26 A. J. Meuler, J. D. Smith, K. K. Varanasi, J. M. Mabry, G. H. McKinley and R. E. Cohen, ACS Appl. Mater. Interfaces, 2010, 2, 3100-3110.

27 R. S. Seymour and P. Schultze-Motel, Nature, 1996, 383, 305.

28 R. S. Seymour and P. Schultze-Motel, Philos. Trans. R. Soc., B, 1998, 353, 935-943.

29 R. S. Seymour and P. Schultze Motel, Endeavour, 1997, 21, 125-129.

30 W. Barthlott, C. Neinhuis, D. Cutler, F. Ditsch, I. Meusel, I. Theisen and H. Wilhelmi, Bot. J. Linn. Soc., 1998, 126, 237-260.

31 S. Camazine and K. J. Niklas, Am. J. Bot., 1984, 71, 843-850.

32 K. Ito, T. Ito, Y. Onda and M. Uemura, Plant Cell Physiol., 2004, 45, 257-264.
33 Anon., Chem. Ind., 1950, 67, 559.

34 V. Hejazi, K. Sobolev and M. Nosonovsky, Sci. Rep., 2013, 3, 2194.

35 S. Jung, M. Dorrestijn, D. Raps, A. Das, C. M. Megaridis and D. Poulikakos, Langmuir, 2011, 27, 3059-3066.

36 R. Menini and M. Farzaneh, Surf. Coat. Technol., 2009, 203, 1941-1946.

37 P. Kim, T. Wong, J. Alvarenga, M. J. Kreder, W. AdornoMartinez and J. Aizenberg, ACS Nano, 2012, 6, 6569-6577.

38 L. Zheng, Z. Li, S. Bourdo, K. R. Khedir, M. P. Asar, C. C. Ryerson and A. S. Biris, Langmuir, 2011, 27, 9936-9943.

39 R. Shabani and H. J. Cho, Microfluid. Nanofluid., 2013, 15, 587-597.

40 M. Nosonovsky and B. Bhushan, J. Phys.: Condens. Matter, 2008, 20, 395005.

41 A. K. Pathan, J. Bond and R. E. Gaskin, Micron, 2008, 39, 1049-1061.

42 K. W. Kim, Micron, 2008, 39, 976-984.

43 A. Marmur, Langmuir, 2004, 3517-3519.

44 K. L. Cho, A. H. - Wu, I. I. Liaw, D. Cookson and R. N. Lamb, J. Phys. Chem. C, 2012, 116, 26810-26815.

45 F. Chang, S. Hong, Y. Sheng and H. Tsao, Appl. Phys. Lett., 2009, 95, 064102.

46 E. N. Kozen, Master of Science, Indiana University of Pennsylvania, 2013.

47 T. Wong, S. H. Kang, S. K. Y. Tang, E. J. Smythe, B. D. Hatton, A. Grinthal and J. Aizenberg, Nature, 2011, 477, 443-447.

48 F. Zhang, L. Zhao, H. Chen, S. Xu, D. G. Evans and X. Duan, Angew. Chem., Int. Ed., 2008, 47, 2466-2469. 